\title{
Psychiatric inpatient care: where do we go from here?
}

\author{
C. Samele ${ }^{1,2 *}$ and N. Urquía ${ }^{2,3}$ \\ ${ }^{1}$ Institute of Mental Health, Nottingham, UK \\ ${ }^{2}$ Director of Informed Thinking Ltd, London, UK \\ ${ }^{3}$ Institute of Psychiatry, Psychology and Neuroscience, King's College London, London, UK
}

The significant decline in the number of psychiatric hospital beds for more than two decades across Europe has changed the landscape of mental health services. This has rekindled debates about bed shortages and the reasons for variations in the number of inpatient beds, admissions to hospital and length of stay. Analysis of European Union (EU) level data shows that the UK has a relatively low number of admissions to hospital, yet a much higher than average length of stay compared with 12 other EU Member States. Understanding this is difficult, but recent studies shed some further light on the patterns and predictors of admissions and length of stay.

Received 2 April 2015; Accepted 1 July 2015

Key words: Bed shortages, Europe, inpatient care, length of stay.

\section{Introduction}

The significant decline in the number of psychiatric hospital beds for more than two decades across Europe has changed the landscape of mental health services. According to Eurostat data the median number of psychiatric hospital beds in 2000 for 28 EU countries was 97.3 per 100000 population; and by 2011 this had fallen to 68.2 per 100000 population (Eurostat, 2015). Despite this substantial drop a number of countries continue to rely heavily on hospital-based care (e.g., Belgium, Malta, Latvia, the Netherlands; see Fig. 1). Some countries have even reversed this downward trend and increased their psychiatric beds (e.g., Croatia, Germany, Latvia, Lithuania) (Eurostat, 2015).

More recently, the reduction in psychiatric inpatient beds has generated some outcry. In England, concerns have been raised about the closure of too many beds, where the average bed occupancy for many NHS Trusts $(n=28)$ is $100 \%$. It is argued to be an 'inefficient and unsafe' system because of these significant bed reductions (Baggaley, 2013).

It is well known that variations exist across regions concerning psychiatric inpatient admissions, length of stay and total bed days across Europe. In 2009, for example, the number of adult psychiatric beds per 100000 population of working age in England ranged from 0.8 in the South East, to 8.0 in London; with an average of 1.6 for England as a whole. There was also a sixfold variation in admission rates across

* Address for correspondence: C. Samele, Institute of Mental Health, Nottingham and Director of Informed Thinking, 10 Grove Road, London SW19 1BL, London, UK.

(Email: informedthinking@gmail.com)
NHS Trusts, a 20-fold variation in total bed days and a 15-fold variation in the average length of stay (Audit Commission, 2010).

What is the current situation for acute psychiatric inpatient care and how does the UK compare with other EU countries?

\section{Inpatient bed numbers}

Figure 1 charts the number of psychiatric beds per 100000 population across the EU Member States. Countries such as Italy have very low numbers of psychiatric beds, about ten beds per 100000 population, and these are exclusively located within general hospital units and not psychiatric hospitals. The UK has fewer psychiatric inpatient beds compared with other European countries at 53 beds per 100000 population.

This is also the case for the number of inpatient admissions.

\section{Inpatient admissions and length of stay}

Figures provided by the WHO European Hospital Morbidity Database (WHO European data are for 2012, except for Denmark (2006), Croatia (2013) and Slovakia (2011)) for 12 EU Member States show the number of inpatient admissions of patients diagnosed with schizophrenia in EU countries ranges from 0.02 to 3.1 per 1000 population (see Fig. 2). The UK has one of the lowest admission rates -0.29 per 1000 population - for this diagnosis compared with 12 other EU countries.

However, the picture changes dramatically when length of stay is examined for the same diagnosis. The average length of stay in days for the UK far exceeds 


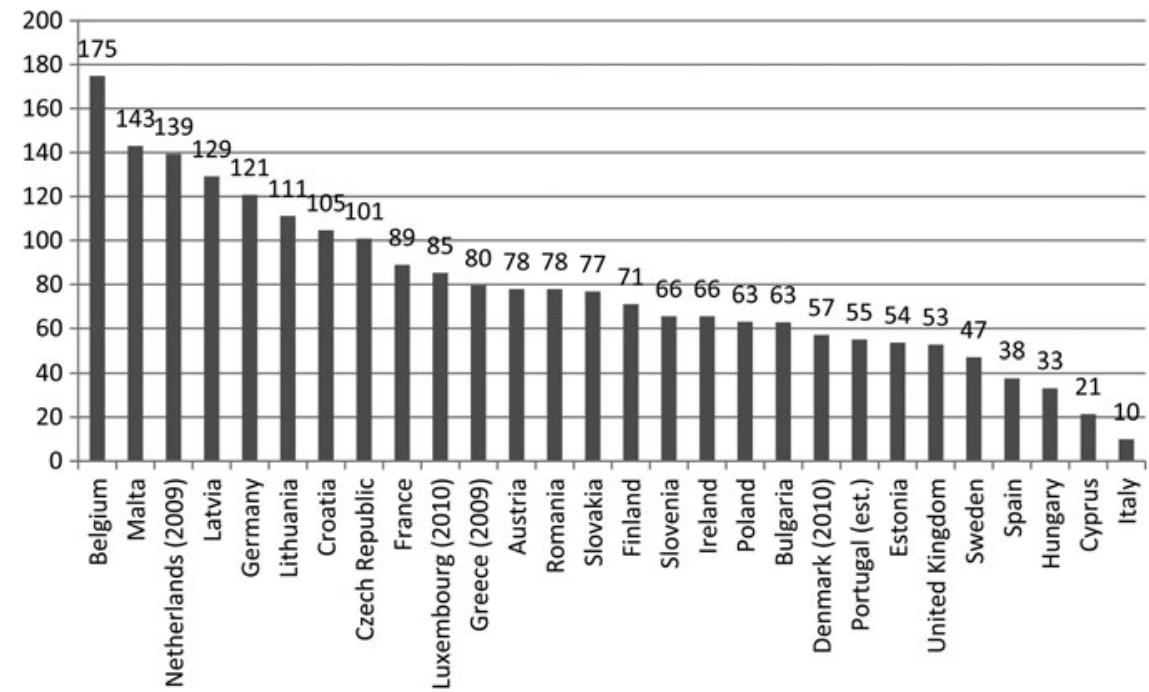

Fig. 1. Number of psychiatric care beds in hospitals (per 100000 population) in 2011 by EU country. Source: Eurostat (2105).

these other countries; and is even higher than countries that still have long-stay hospital care, such as Malta (see Fig. 3).

Based on descriptive analyses of EU level data by Samele et al. (2013), the rate of inpatient admissions when plotted alongside the average length of stay show that the UK's low admission rate but high average length of stay differs considerably compared with just under half of other EU countries (see Fig. 4). The average length of stay is 131.7 days for the UK which contrasts markedly to that of Denmark at 5.5 days as shown in Fig. 2. Latvia, by contrast has a higher number of admissions to psychiatric hospital with a relatively short average length of stay.

What is alarming is that length of stay in the UK appears to be rising. The same data collected from the WHO European Hospital Morbidity Database in 2012 reveal that the average length of stay for the UK was 110.0 days; an average increase therefore of circa 22 days.

\section{Predictors of length of stay}

Surprisingly little recent research exists on the patterns and predictors of length of stay in the hospital. The reasons for length of stay is complex and affected by multiple factors, including the structure of mental health systems, cultural factors and the pressure to discharge patients much earlier (Sytema et al. 2002; Auffarth et al. 2008).

A study by Zhang et al. (2011) found ten factors associated with length of stay, particularly seclusion during the index admission, problems with accommodation and living in an area with few communitybased services. One study focused on the impact of

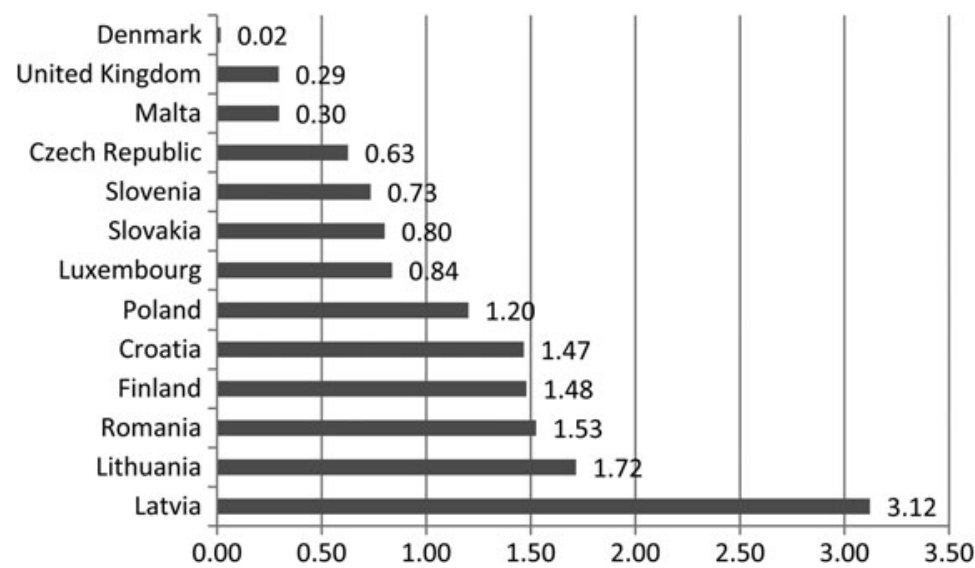

Fig. 2. Number of psychiatric inpatient admissions per 1000 population by EU country for patients diagnosed with schizophrenia. Source: WHO European Hospital Morbidity Database (2015). 


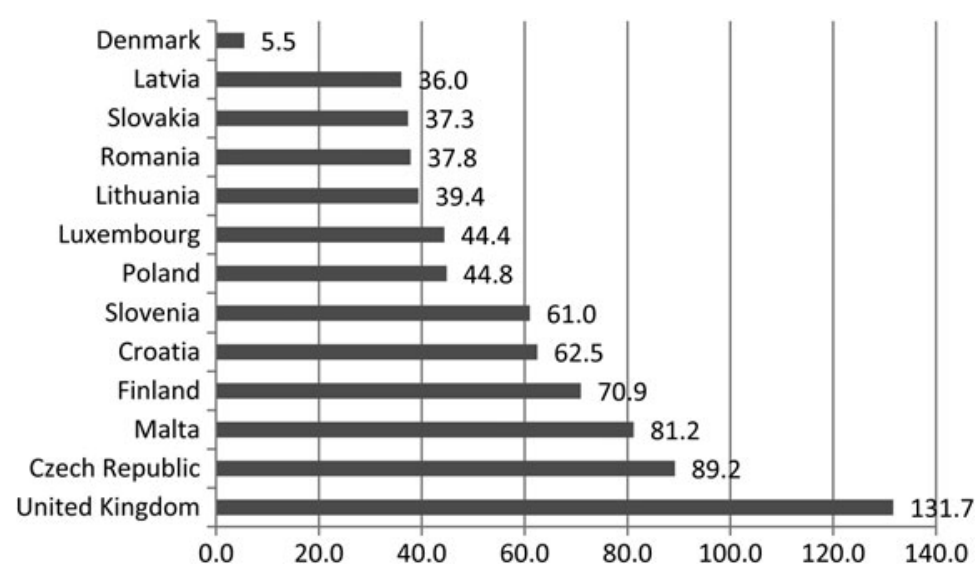

Fig. 3. Average length of stay (days) for patients with schizophrenia. Source: WHO European Hospital Morbidity Database (2015).

medical comorbidity on length of stay (Douzenis et al. 2012). Two of the hypotheses tested aimed to examine whether severe comorbidity requiring referral in patients with schizophrenia and bipolar disorder would affect length of stay and what factors were associated with it. A total of 428 patients were included in the sample, 200 of whom had a diagnosis of schizophrenia. Arterial hypertension was the most common medical condition for patients with bipolar and those with schizophrenia mostly had an endocrine/metabolic disease. The investigators found a significant linear positive relationship between patients with schizophrenia and severe comorbidity and length of stay. The number of prolonged days was significant (up to a median of 13 days) depending on the number of referrals made.

The implications of Douzenis et al.'s (2012) study are interesting and highlight the importance of addressing physical health problems in people with severe mental illness. It is important to note that the study was based on an inpatient sample in Greece where the provision of comprehensive community-based mental health care may not have been available. Even primary care services in Greece are relatively underdeveloped which could have had the knock on effect of increasing length of stay.

Explaining why the UK has a higher than average length of stay compared with some other EU countries is tricky, not least because the UK has a very welldeveloped and well-resourced system of health and mental health care. The shortage of inpatient psychiatric beds has made it increasingly more difficult for people to gain access to these services. A similar situation has occurred internationally. In Victoria, Australia, for example, a high level of symptom severity appears necessary in order to access inpatient beds; which has provoked strong dissatisfaction among service users and carers (cited in Zhang et al. 2011).

\section{Compulsory admissions}

Bed shortages have also led to the acceleration of compulsory admissions which have been rising for over two decades. To shed light on this, a recent study by

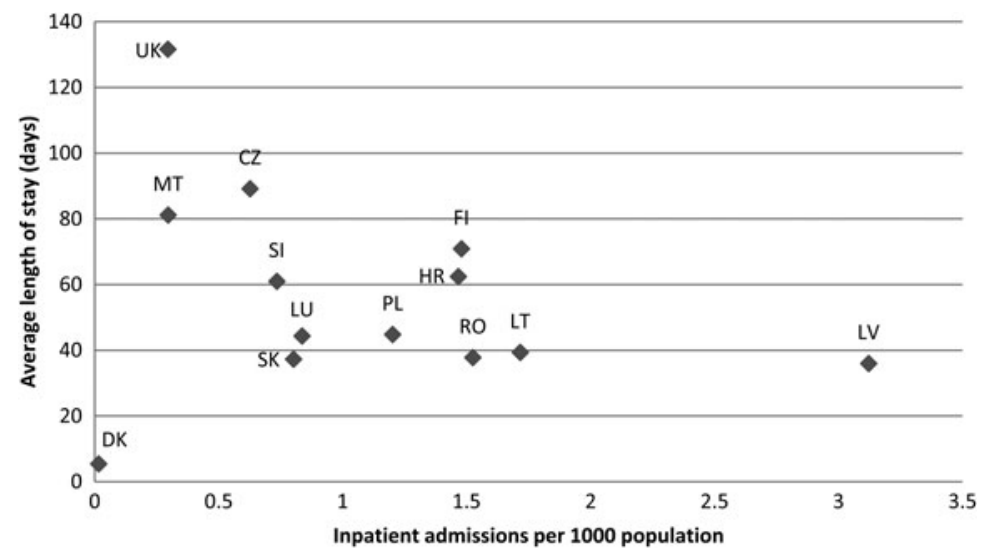

Fig. 4. Average length of stay (days) for people diagnosed with schizophrenia by inpatient admissions per 1000 population. Source: WHO European Hospital Morbidity Database (2015). 
Weich et al. (2014) analysed a dataset of 1238188 patients who received mental health care in 2010/ 2011. The authors found that $84.5 \%$ of the variance in the rate of compulsory admissions occurred between individuals (patient gender, age, ethnicity) and 6.7\% between local areas, $2.7 \%$ between GP practices and $6.9 \%$ between provider Trusts. There was a small but significant association between higher bed occupancy and compulsory admission which disappeared after adjustment for confounders. The authors conclude there remains a need to reduce compulsory admissions and for further research in this area.

\section{Intensive case management}

The high number of compulsory admissions happens even where well-resourced specialist communitybased mental health services are available. In attempting to understand the inconsistent effects of intensive case management, Burns et al. (2007) conducted a systematic review and meta-regression. Trials with high hospital use prior to the trial or in the control group were likely to show that intensive case management reduced the use of inpatient care (coefficient -0.23 , $95 \%$ confidence interval -0.36 to -0.09 , for hospital use at baseline; $-0.44,-0.57$ to -0.31 , for hospital use in control groups). Hence, intensive case management works best in areas where hospital use is high and is less effective where hospital use is already low.

\section{Cost of inpatient psychiatric care}

The proportion of expenditure for mental health services allocated to inpatient care remains high for some countries, particularly those with long-stay psychiatric hospitals, although not exclusively. According to figures produced by the WHO (2011), Malta, for example, spends $96.8 \%$ of its mental health budget on hospital care. Poland, despite not having long-stay hospitals, spends $73.0 \%$ of its mental health budget on inpatient services. This high proportion of funding devoted to inpatient mental healthcare inevitably restricts the amount of investment/resources allocated to developing community mental health services.

In the UK, it costs approximately $£ 300$ a day for adult acute psychiatric inpatient care and double this for psychiatric intensive care (PSSRU, 2010). If length of stay is relatively high, as in the UK, then inpatient costs will remain high. McCrone et al. (2008) assessed the need for mental health services, their current and projected costs up until 2026 and the potential cost savings of specific interventions. The authors found that savings, largely in the form of reduced inpatient costs in the UK could be achieved by expanding the use of crisis intervention/home treatment and early intervention services for people with schizophrenia and bipolar disorder and related conditions. Indeed, home treatment/crisis services appear to reduce admissions to hospital and duration of inpatient stay (Centre NHS Information, 2009; McCrone et al. 2009). This may mean shifting the balance of care in favour of not only more community-based crisis intervention, but also more research to understand the finer detail of how higher than average length of stay can safely be reduced and without drastic cost-cutting measures.

\section{Conclusion}

Despite the substantial reductions in psychiatric beds over the past two decades, inpatient care remains an important component of any mental health system; as is a comprehensive range of community-based services (Thornicroft \& Tansella, 2013). Some EU countries rely heavily on psychiatric inpatient care which consumes a large proportion of the financial resources allocated to mental health services.

Even though the UK has relatively fewer psychiatric inpatient beds and a low rate of admissions to hospital, it has an alarmingly long average length of stay compared with other EU Member States. Recent evidence to understand why this is the case is very limited.

This coupled with a general lack of evidence regarding most aspects of acute inpatient care limits any informed decisions about what next in terms of policy and clinical practice.

Improving the evidence base of how inpatient care can be used more effectively is crucial, particularly as these are high cost services. Therefore, further research to understand why the average length of stay in the UK is relatively long and how this can be brought in line with other European countries would be of great benefit to all concerned.

\section{Acknowledgements}

We are grateful to the European Commission funding body - Consumers, Health, Agriculture and Food Executive Agency - who funded the project which formed the basis of this editorial.

\section{Financial Support}

This research received no specific grant from any funding agency, commercial or not-for-profit sectors.

\section{Conflict of Interest}

None. 


\section{References}

Audit Commission (2010). Maximising resources in adult mental health. Retrieved March 2015 from http://archive. audit-commission.gov.uk/auditcommission/SiteCollection Documents/Downloads/20100623mentalhealthbriefing.pdf

Auffarth I, Busse R, Dietrich D, Emrich H (2008). Length of psychiatric inpatient stay: comparison of mental health care outlining a case mix from a hospital in Germany and the United States of America. German Journal of Psychiatry 11, 40-44.

Baggaley M (2013). England's mental health services in crisis. BBC News. Retrieved March 2015 from http://www.bbc.co. uk/news/health-24537304

Burns T, Catty J, Dash M, Roberts C, Lockwood A, Marshall M (2007). Use of intensive case management to reduce time in hospital in people with severe mental illness: a systematic review and meta-regression. British Medical Journal. doi: 10.1136/bmj.39251.599259.55.

Centre NHS Information (2009) Mental health bulletin: third report from mental health minimum dataset (MHMDS) annual returns, 2004-2009: Department of Health. Retrieved June 2015 from http://www.ic.nhs.uk/pubs/ mhbmhmds0809

Douzenis A, Seretis D, Nika S, Nikolaidou P, Papadopoulou A, Rizos EN, Christodoulou C, Tsopelas C, Mitchell D, Lykouras L (2012). Factors affecting hospital stay in psychiatric patients: the role of active comorbidity. BMC Health Services Research 12, 166.

European Hospital Morbidity Database (2015) World Health Organization Regional Office for Europe. Retrieved March 2015 from http://data.euro.who.int/hmdb/

Eurostat (2015). Psychiatric care beds in hospitals. Retrieved March 2015 from http://ec.europa.eu/eurostat/tgm/.do?tab= table\&plugin $=1 \&$ language $=$ en\&pcode $=$ tps 00047

McCrone P, Dhanasiri S, Patel A, Knapp M, Lawton-Smith S (2008). Paying the price. The cost of mental health care in England to 2026. King's Fund. Retrieved April 2015 from http://www.kingsfund.org.uk/sites/files/kf/Paying-the-
Price-the-cost-of-mental-health-care-England-2026-McCroneDhanasiri-Patel-Knapp-Lawton-Smith-Kings-Fund-May2008_0.pdf

McCrone P, Johnson S, Nolan F, Sandor A, Hoult J, McKenzie N, White IR, Bebbington P (2009) Impact of a crisis resolution team on service costs in the UK. Psychiatric Bulletin 33, 17-19. Retrieved June 2015 from http://pb. rcpsych.org/content/33/1/17

PSSRU (2010). Unit costs of health and social care, 2010. Retrieved April 2015 from http://www.pssru.ac.uk/pdf/uc/ uc2010/uc2010_s07.pdf.PersonalSocialServicesResearchUnit

Samele C, Frew S, Urquia N (2013). Mental Health Systems in the European Union Member States, Status of Mental Health in Populations and Benefits to be Expected from Investments into Mental Health (EUROPOPP Project). A Report Prepared on Behalf of the Institute of Mental Health, Nottingham for the EU Executive Agency for Health and Consumers. Retrieved March 2015 from http://ec.europa.eu/health/mental_health/ docs/europopp_full_en.pdf

Sytema S, Burgess P, Tansella M (2002). Does community care decrease length of stay and risk of rehospitalisation in new patients with schizophrenia disorder? Schizophrenia Bulletin 28, 273-281.

Thornicroft G, Tansella M (2013). The balanced care model: the case for both hospital- and community-based mental healthcare. British Journal of Psychiatry 202, 246-248.

Weich S, Mcbride O, Twigg L, Keown P, Cyhlarova E, Crepaz-Keay D, Parsons H, Scott J, Bhui K (2014).

Variation in compulsory psychiatric inpatient admission in England: a cross-sectional, multilevel analysis. Health Service Delivery Research 2. doi: 10.3310/hsdr02490.

WHO (World Health Organization) (2011) Mental Health Atlas 2011. Retrieved July 2015 from http://whqlibdoc.who. int/publications/2011/9799241564359_eng.pdf

Zhang J, Harvey C, Andrew C (2011). Factors associated with length of stay and the risk of readmission in an acute psychiatric inpatient facility: a retrospective study. Australian and New Zealand Journal of Psychiatry 45, 578-585. doi: 10.3109/00048674.2011.585452. 